\title{
The Ratio of Verbal and Nonverbal Components of Individual Cognitive Maps as a Reflection of the Collaborative Thinking Activity of Its Participants
}

\author{
Denis F. Dautov' \\ 'Don State Technical University, Faculty of "Psychology, Pedagogy, Defectologists", Department of Educational Psychology \\ and Organizational Psychology Rostov-on-Don, Russian Federation, e-mail: dautov-80@mail.ru
}

\begin{abstract}
The presented results of the study allow us to determine the ratio of verbal and nonverbal components of thinking activity in solving problems of different types. The novelty of the research is in the use of individual cognitive maps made on the results of collaborative thinking activity in the study of possible combinations of symbolic (verbal) and figurative (nonverbal) components of internal thought processes implemented in different conditions. The study included two methodological blocks. The first of them is diagnostic. It consisted of four tasks (a verbal task with one solution, a verbal task with multiple solutions, a nonverbal task with one solution, a nonverbal task with multiple solutions), as well as a cognitive map based on the results of solving these tasks. The second block is mathematical and statistical, including the Kruskal-Wallis H-test, the Mann-Whitney U-test, and the Fried-man chi-square test. The study sample consisted of 80 students of the Don State Technical University. As a result of the study, it was found that cognitive maps created with time constraints significantly outperform cognitive maps created without such restrictions in terms of figurative, symbolic abstractness and symbolism. Cognitive maps created without time constraints significantly outperform cognitive maps created with time constraints in terms of imagery. In general, the predominance of the verbal or nonverbal components of thinking can vary significantly, but the general trend towards the predominant character of the imagery of thought processes remains.
\end{abstract}

Keywords: thinking activity, cognitive map, mental map, components of thinking activity.

\section{Introduction}

The theory and practice of cognitive mapping is extremely diverse. The concept of this phenomenon changed from an image that captured the external reality to a complex network of verbal and nonverbal representations (Solso, MacLin, and MacLin, 2014; Eden, 2004; Nesbit and Adescope, 2006). However, despite all this diversity, cognitive maps, as a rule, tend to be considered more as a convenient tool for thinking than a tool for understanding the psyche. Such understanding exists despite the fact that it is cognitive maps, due to their projective nature, that allow us to present internal thought processes in an external form that is accessible to the researcher (Solso, MacLin, and MacLin, 2014; Nesbit and Adescope, 2006). This also applies to the manifestations of the unconscious and, most importantly, the interaction of conscious and unconscious processes of the human psyche. Many questions of this interaction remain unclear, and it is largely unclear how the various manifestations of the conscious and unconscious relate to each other. The study of the ratio of verbal and nonverbal components of cognitive maps allow us to look deeper into the internal mental processes, to understand what conscious and unconscious mechanisms are involved in the implementation of thinking activity (Bottini and Doeller, 2020; Nanay, 2021).

The first mention of this term was made by E. Tolman in 1948 (Tolman, 1948). His research was continued, at the level of human thinking in the work of R. Downes, D. Stey, (Downs and Stea, 2017). In this study, along with the concept of "cognitive map", another one was used - "psychological map". In general, a psychological map is a structured and ordered representation of reality, making it more concrete, but not reducible to model stimuli.

Another similar term in terms of content is the "mental map" considered in line with the concepts

"Corresponding author: dautov-80@mail.ru 
of K. Lynch, S. Milgram and S. Fauconnier (Filomena, Verstegen and Manley, 2019; Milgram, 1970; Fauconnier, 2018). By mental maps, these researchers meant an image of how a person imprints the object world around him in his mind (Milgram, 1970; Beel and Langer, 2011).

In the future, the term "cognitive map" was interpreted more and more broadly, in the form of a metaphor for a certain set of ideas. So J. L. Bellmund defines the cognitive map as a set of visual representations of reality, a kind of mental images as such (Bellmund et al., 2018). Subsequently, the idea of cognitive maps as exclusively visual representations is questioned. A number of researchers are beginning to perceive it more as a conceptual scheme. In this capacity, under the name "concept map", it was first described by J. Novak. It is presented as a technique of visual representation of the information structure, which reflects the interaction of concepts in the conceptual field (Novak, 2010; Cañas, Novak and Reiska, 2015). Further development, but already under the name of the intellect map or mind map, the conceptual map was received in the works of T. Buzen, which in his view is a graphic representation of semantic, causal or associative connections between concepts, parts and components of the considered area (Behrens, et al. 2018; Sadoski and Paivio, 2013). Thus, the cognitive map, along with the nonverbal, imaginative dimension, has a second - verbal dimension, and the problem of the interaction of these two components in the human psyche arises.

One of the first works devoted to the problem of the correlation of verbal and nonverbal forms in the dynamics of thinking activity was the work of A. Paivio. In his research, he came to the assumption of the existence of two coding systems - figurative and symbolic (Sadoski and Paivio, 2013; Paivio, 2011).

R. Finke, testing the hypothesis of A. Paivio, came to the conclusion that both codes can be implemented in human thinking activity either together or separately from each other (Ward, Finke and Smith 2013; Palmiero, et al., 2019).

The presence of psychic constructs confirms this possibility. Mental constructs are verbal concepts that construct the essence of the surrounding world (Palmiero, et al., 2019). According to N. Smith, the mental construct is a product of theorizing and abstraction, i.e., the complete opposite of the figurative representation of reality (Ward, Finke and Smith 2013).

However, in their recent studies of mnemonic processes, A. Paivio and M. Sadoski, determined that when working with information, a person uses both methods of encoding. Initially, the incoming information is translated into figurative, and only then into verbal form, and in the case of abstract concepts, images act as "hints" that facilitate thinking activity (Sadoski and Paivio, 2013).

The transition of symbolic processes into visual ones and, conversely, in cognitive maps is often barely perceptible, and in most cases is realized by a person on an unconscious level (Solso, MacLin and MacLin, 2014; Rosch, 2011; Park et al., 2020).

$R$. McAleese, developing the ideas of $P$. Chandler, in a number of his articles, speaks about the ability of a person, using cognitive maps, to be aware of the information received, extracting it from the unconscious, to clearly see the process of thinking (McAleese, 1998; Sweller, 2020).

A number of researchers believe that the conscious and unconscious are not just different areas of the psyche, acting as repositories of thoughts and memories, they have different ways of interacting with the surrounding reality (Sadoski and Paivio, 2013; Dehaene et al., 2014). In this case, we can already talk about the cognitive conscious and the unconscious. These terms, introduced into scientific use by P. Rozin back in 1976, are still not well established. The idea of the cognitive unconscious was developed by S. Epstein, and later by a number of other specialists in cognitive psychology (Epstein, 2012). To date, the cognitive unconscious is understood as the processing of information that occurs in addition to thought, bypassing consciousness. B. Baars generalized the ideas of $S$. Epstein and a number of other cognitive psychologists, created the theory of the global workspace. According to B. Baars, consciousness arises from the unconscious or preconscious, forming a global workspace (Baars, 2017). Cognitive neuropsychologist S. Dehaene, while studying the mechanisms of translation from unconscious perception to conscious perception, came to the conclusion that all events that occur in consciousness must initially occur in the unconscious and have a nonverbal form (Dehaene, 2011; Dehaene et al., 2014). D. Stern emphasized that the basis for the unconscious is nonverbal thinking, based on the language of images, and the basis of conscious is logical-verbal thinking, operating with verbal representations (Stern, 2015). A. Dijksterhuis, after a series of experiments, came to the conclusion that since a significant part of memory is unconscious, unconscious thinking is superior to conscious thinking in those areas that require a qualitative, simultaneous comparison of many alternatives (Dijksterhuis and Aarts 2010). Consequently, beyond the boundaries of consciousness are phenomena that are not subject to verbal processing, but are processed at the nonverbal level, forming the sphere of the cognitive unconscious. Of course, conscious is not limited to the verbal form, just as the unconscious is not limited to nonverbal forms. However, the verbal for conscious, as well as the nonverbal for the unconscious, are an absolute basis, as confirmed by 
numerous studies in cognitive psychology, psychophysiology, and neuropsychology (Sadoski and Paivio, 2013; Dehaene, 2011; Stern, 2015; Behrens, et al. 2018).

Thus, the process of interaction of the verbal and nonverbal components of the subject's thought processes in the cognitive map makes it possible to trace how the unconscious component of the psyche, which is reflected in the visual form, interacts with the conscious component, which reflects the verbal and logical component of the psyche.

The study of such transitions in cognitive maps at the level of joint activity allows us to study it in a manifest, external form, whereas in individual activity, phenomena are inaccessible to an external observer, because of their convolution and non-manifestation in an external, observable form.

\section{Materials and Methods}

The study involved 80 subjects ( 24 men and 56 women) aged 20 to 24 years. Subjects - bachelors of the 3-4 courses and masters of the 1 course (humanities and technical specialties) of Don State Technical University.

In the course of the study, each student group was asked to divide into subgroups of four people each, based on their personal preferences. A total of 20 small groups were obtained.

The formed groups of subjects were given four tasks. Half of the groups of subjects received the first and second tasks to solve, the second half of the groups were given the third and fourth tasks. This was done to ensure that the subjects solved the most different problems from each other, and the experience of solving one problem did not affect the solution of the other. In addition, half of the subjects solved the problems without having a time limit. The other half, had to meet a certain time frame, when solving problems. This was done to stimulate the unconscious component of thinking, which increases with a decrease in the resource of time.

The first of them was to remove a certain number of lines that make up the sides of a square and add a certain number of lines in return, to get a different number of squares than what was originally presented in the conditions of the problem. You need to find only one option that fully meets the conditions of the problem. To facilitate the thought process, its greater clarity, the squares were assembled from matches. The second task was to find a way to break a vase full of water, located in a locked room, without leaving a trace, while being in the building opposite. In this case, it was necessary to offer all possible ways that guaranteed success. The third task asks the subjects to draw three straight lines, through four points arranged in squares, without lifting the pencil from the sheet of paper so that all the points are connected, and the pencil returns to the starting point. It was necessary to find all possible ways to do this. The fourth task is about two twins, one of whom must be caught in a lie knowing that one of them always tells the truth, and the other always lies. It is necessary to find the only possible formulation that allows this to be done.

Each of the proposed tasks has a certain combination of parameters. The first task is nonverbal in nature and has a single solution within the framework of the formulated conditions. The second task is verbal, having many ways to solve it. The third task is nonverbal in nature, and has many possible solutions. The fourth task is verbal in nature, also having only one solution. Thus, the four tasks are a combination of certain parameters highlighted as the main ones and allow you to alternately use certain components of the psyche.

Thus, the verbal nature of the task inclines the subjects to engage in verbal-logical thinking, which is based on the conscious component of the psyche, while nonverbal tasks, on the contrary, promote the use of imaginative thinking and, therefore, rely more on the unconscious component of the psyche. The presence of provided alternatives in the results of solving the problem should also contribute to the activation of the conscious, if there are several possible solutions or activation of the unconscious, the latter better copes with the need for a qualitative comparison of alternatives among themselves, to choose the only way to solve the problem. solutions.

Before working with the tasks, all the subjects were informed whether the task has one or more

After solving all the problems, students were asked to individually depict the process of group solving one of the four problems in a graphical form. Each of them could represent the solution of only one problem. Students were not required to seek help from other members of the group. Before starting work, the study participants had to agree with each other on the solutions to which problem they would represent. This was done to get an equal number of images for each of the presented tasks. At the same time, those subjects who solved problems in the presence of time constraints were instructed to build 
a cognitive map for a certain period of time, equal to three minutes. This was done so that the study participants did not have time to create a conscious plan for the future map and were forced to rely on the unconscious component of the psyche. The other half of the subjects did not have such restrictions, and could more consciously approach the creation of a cognitive map. Thus, ten cognitive maps were obtained for each of the tasks.

The drawn image created by the student could have explanations in the form of individual words or short phrases. Assignments for students were submitted in a free form, with high uncertainty. Thanks to this, the construction of cognitive maps was made less formal, which contributed to a more flexible approach to their representation and allowed us to overcome the limitations of focusing on the formal criteria of cognitive maps. The resulting cognitive maps were evaluated according to four indicators.

The first such indicator was figurative abstractness, understood as the presence of images distant from specific images. The number of abstract images was taken into account, the more of them, the higher the abstractness of the cognitive map. The presence of $25 \%$ or less of abstract images from the total number in the drawing indicated a low abstractness. From $25 \%$ to $50 \%$ of abstract images meant that the map has an average level of abstractness. If such images were from $50 \%$ to $75 \%$, the abstractness of the cognitive map was defined as high, more than $75 \%$ as very high. Thus, a particular cognitive map could get from 1 point for low abstractness to 4 points for high abstractness.

The second indicator was symbolic abstractness, understood as the degree of remoteness of the verbal component of the map from specific concepts. The method of evaluation was the same as in the first case.

The third indicator is imagery (nonverbality), defined as the number of images used in the cognitive map. The number and method of awarding points was the same as in the case of the previous indicator.

The fourth indicator is symbolism (verbality). This is the number of verbal objects in the cognitive map. If the number of words did not exceed 4 , then the symbolism was determined as low and was indicated by one point. The cognitive map, which included from 5 to 8 words, was defined as having an average level of symbolism, which brought 2 points. A map in which from 9 to 12 objects were determined to have a high level and were rated at 3 points. A map with more than 12 objects was defined as having a very high level of symbolism, which was estimated at 4 points.

Mathematical and statistical data processing was performed using the Kruskal-Wallis H-test, the Mann-Whitney U-test, and the Friedman chi-square test.

\section{Results}

The indicators of cognitive maps were brought to the average values for each of the four tasks. The results obtained are divided into five main blocks. The first section provides data on the differences in each individual indicator of cognitive maps based on the results of solving all types of tasks, by those subjects who were not limited in time when creating these maps. The second section provides data on the differences between all the indicators of cognitive maps, performed as a result of solving each individual type of tasks, by subjects who were not limited in time when creating these maps. The third section provides data on the differences in each individual indicator of cognitive maps based on the results of solving all types of tasks, by those subjects who were limited in time when creating maps. The fourth block provides data on the differences between all the indicators of cognitive maps, performed as a result of solving each individual type of tasks, by subjects who were limited in time when creating maps. The fifth block demonstrates the results of the study on the presence of differences between the indicators of the cognitive maps of the subjects who were limited in time, and those for whom there were no such restrictions. To obtain the results of the first and third blocks, the Kruskal-Wallis H-test was used. To obtain the results of the second and fourth blocks of the criterion, the Friedman chi-square was used. To get the results of the fifth block, use the Mann - Whitney U-test.

Table 1 shows the results of a study of the differences between the indicators of cognitive maps performed after solving all four tasks, without time limits. 
Table 1

Differences in each individual indicator of cognitive maps performed without time constraints, based on the results of solving all types of tasks

\begin{tabular}{|c|c|c|c|c|c|c|c|c|}
\hline \multirow{3}{*}{ Types of tasks } & \multicolumn{8}{|c|}{ Indicators of cognitive maps } \\
\hline & \multicolumn{2}{|c|}{$\begin{array}{c}\text { Figurative } \\
\text { abstractness }\end{array}$} & \multicolumn{2}{|c|}{$\begin{array}{c}\text { Symbolic } \\
\text { abstractness }\end{array}$} & \multicolumn{2}{|c|}{ imagery } & \multicolumn{2}{|c|}{ Symbolism } \\
\hline & $\begin{array}{l}\text { Average } \\
\text { values }\end{array}$ & $\begin{array}{c}\text { Difference } \\
\text { indicator }\end{array}$ & $\begin{array}{l}\text { Average } \\
\text { values }\end{array}$ & $\begin{array}{l}\text { Difference } \\
\text { indicator }\end{array}$ & $\begin{array}{c}\text { Average } \\
\text { values }\end{array}$ & $\begin{array}{l}\text { Difference } \\
\text { indicator }\end{array}$ & $\begin{array}{c}\text { Average } \\
\text { values }\end{array}$ & $\begin{array}{c}\text { Difference } \\
\text { indicator }\end{array}$ \\
\hline Task 1 & & & & & & & & \\
\hline $\begin{array}{l}\text { Nonverbal, with one } \\
\text { solution option } \\
\text { Task } 2\end{array}$ & 2,9 & & 1,6 & & 3,4 & & 2,2 & \\
\hline $\begin{array}{l}\text { Verbal, with multiple } \\
\text { solutions }\end{array}$ & 1,6 & & 1,9 & & 2,1 & & 3,1 & \\
\hline Task 3 & & $13,87^{\star \star}$ & & 3,21 & & $19,31^{* *}$ & & $10,32^{*}$ \\
\hline $\begin{array}{l}\text { Nonverbal, with } \\
\text { multiple solutions } \\
\text { Task } 4\end{array}$ & 2,0 & & 2,0 & & 2,7 & & 3,0 & \\
\hline $\begin{array}{l}\text { Verbal, with one so- } \\
\text { lution option }\end{array}$ & 2,0 & & 1,6 & & 2,1 & & 2,1 & \\
\hline
\end{tabular}

Note: ${ }^{* * *} p \leq 0,001 ;{ }^{* *} p \leq 0,01 ;{ }^{*} p \leq 0,05$.

According to the presented data, significant differences obtained using the Kruskal-Wallis H-test were found between such indicators of cognitive maps as figurative abstractness (hemp. $=13.87 ; p \leq 0.01$ ), imagery (hemp. $=19.31 ; p \leq 0.01$ ) and symbolism (hemp. $=10,32 ; p \leq 0,05)$. At the same time, the subjects showed the highest indicators of figurative abstractness of cognitive maps when solving the first task (2.9), which has a nonverbal character and is limited to one correct solution. The imagery of the cognitive map was the highest, according to the results of solving the first problem (3.4), as well as in the case of figurative abstraction. The highest indicators of the symbolism of the cognitive map are demonstrated by the subjects after solving the second task - verbal, with several solutions. The differences in such an indicator as symbolic abstractness were insignificant.

Cognitive maps based on the results of verbal tasks are inferior in figurative abstractness and imagery to maps made after solving nonverbal tasks. The figurative abstractness is higher in those maps that were created based on the results of solving a problem with one correct answer. High levels of symbolism are demonstrated by those cognitive maps that were created as a result of solving problems with multiple solutions, whether they were verbal or nonverbal. The index of imagery is higher in those cognitive maps that were created after solving problems with one correct answer, but they were higher after solving nonverbal problems than after solving verbal ones.

After describing the results of comparing the indicators of cognitive maps performed on the basis of different types of tasks, we will consider the data on the differences between all the indicators of cognitive maps performed on the basis of solving each individual type of tasks. The results are presented in table 2. 
Table 2

Differences between all indicators of cognitive maps performed without time constraints, based on the results of solving each individual type of task

\section{Types of tasks}

\begin{tabular}{|c|c|c|c|c|c|c|c|c|}
\hline \multirow[t]{2}{*}{$\begin{array}{l}\text { Indicators of } \\
\text { cognitive maps }\end{array}$} & \multicolumn{2}{|c|}{$\begin{array}{c}\text { Task 1 } \\
\text { Nonverbal, with one } \\
\text { solution option }\end{array}$} & \multicolumn{2}{|c|}{$\begin{array}{c}\text { Task } 2 \\
\text { Verbal, with multiple } \\
\text { solutions }\end{array}$} & \multicolumn{2}{|c|}{$\begin{array}{c}\text { Task } 3 \\
\text { Nonverbal, with multi- } \\
\text { ple solutions }\end{array}$} & \multicolumn{2}{|c|}{$\begin{array}{l}\text { Task } 4 \\
\text { Verbal, with one } \\
\text { solution option }\end{array}$} \\
\hline & $\begin{array}{c}\text { Average } \\
\text { values }\end{array}$ & $\begin{array}{c}\text { Difference } \\
\text { indicator }\end{array}$ & $\begin{array}{c}\text { Average } \\
\text { values }\end{array}$ & $\begin{array}{c}\text { Difference } \\
\text { indicator }\end{array}$ & $\begin{array}{c}\text { Average } \\
\text { values }\end{array}$ & $\begin{array}{c}\text { Difference } \\
\text { indicator }\end{array}$ & $\begin{array}{c}\text { Average } \\
\text { values }\end{array}$ & $\begin{array}{l}\text { Difference } \\
\text { indicator }\end{array}$ \\
\hline $\begin{array}{l}\text { Figurative } \\
\text { abstractness }\end{array}$ & 2,9 & & 1,6 & & 2,0 & & 2,0 & \\
\hline $\begin{array}{l}\text { Symbolic } \\
\text { abstractness }\end{array}$ & 1,6 & & 1,9 & & 2,0 & & 1,6 & \\
\hline imagery & 3,4 & $16,64^{* x}$ & 2,1 & $14,68^{\mathrm{kx}}$ & 2,7 & 5,95 & 2,1 & 4,43 \\
\hline Symbolism & 2,2 & & 3,1 & & 3,0 & & 2,1 & \\
\hline
\end{tabular}

Note: ${ }^{* * *} p \leq 0,001 ;{ }^{* *} p \leq 0,01 ;{ }^{*} p \leq 0,05$.

According to the presented data, significant differences established using the Friedman chi-square test were found between the indicators of cognitive maps that were performed based on the results of solving the first $\left(\chi^{2} r\right.$ emp. $\left.=16.64 ; p \leq 0.01\right)$ and the second task $\left(\chi^{2}\right.$ remp. $\left.=14.68 ; p \leq 0.01\right)$. Among the indicators of cognitive maps performed at the end of the first task, imagery is predominant $(3,4)$. At the same time, high values for figurative abstractness (2.9) indicate the predominance of abstract images in maps that are based on nonverbal tasks, with one possible solution. The indicators of symbolism $(2,2)$ and symbolic abstractness $(1,6)$, on the contrary, are relatively small. In addition, the low values of symbolic abstractness indicate the predominance of the nonverbal component of the cognitive map over the verbal one, in such maps, there are many specific concepts and few generalizations. The indicators of cognitive maps performed on the results of the second task demonstrate the predominance of symbolism $(3,1)$ over imagery $(2,1)$. Indicators of abstractness of both symbolic $(1,9)$ and figurative $(1,6)$ are at a low level. These cognitive maps are dominated by verbal objects - verbal descriptions that are specific in nature. The nonverbal component is noticeably weaker, the images themselves are concrete and inferior in abstraction to the symbolic component.

Consider the results of the second group of subjects who, according to the study conditions, had to create cognitive maps with time constraints. The results are presented in Table 3. 
Table 3

Differences in each individual indicator of cognitive maps performed under time constraints, based on the results of solving all types of tasks

\begin{tabular}{|c|c|c|c|c|c|c|c|c|}
\hline \multirow{3}{*}{ Types of tasks } & \multicolumn{8}{|c|}{ Indicators of cognitive maps } \\
\hline & \multicolumn{2}{|c|}{$\begin{array}{c}\text { Figurative } \\
\text { abstractness }\end{array}$} & \multicolumn{2}{|c|}{$\begin{array}{c}\text { Symbolic } \\
\text { abstractness }\end{array}$} & \multicolumn{2}{|c|}{ imagery } & \multicolumn{2}{|c|}{ Symbolism } \\
\hline & $\begin{array}{c}\text { Average } \\
\text { values }\end{array}$ & $\begin{array}{l}\text { Difference } \\
\text { indicator }\end{array}$ & $\begin{array}{c}\text { Average } \\
\text { values }\end{array}$ & $\begin{array}{c}\text { Difference } \\
\text { indicator }\end{array}$ & $\begin{array}{c}\text { Average } \\
\text { values }\end{array}$ & $\begin{array}{c}\text { Difference } \\
\text { indicator }\end{array}$ & $\begin{array}{c}\text { Average val- } \\
\text { ues }\end{array}$ & $\begin{array}{l}\text { Difference } \\
\text { indicator }\end{array}$ \\
\hline $\begin{array}{c}\text { Task } 1 \\
\text { Nonverbal, with one } \\
\text { solution option } \\
\text { Task } 2\end{array}$ & 3,3 & & 1,8 & & 3,5 & & 2,6 & \\
\hline $\begin{array}{l}\text { Verbal, with multiple } \\
\text { solutions }\end{array}$ & 1,6 & & 2,8 & & 2,0 & & 2,1 & \\
\hline $\begin{array}{l}\text { Task } 3 \\
\text { Nonverbal, with } \\
\text { multiple solutions } \\
\text { Task } 4\end{array}$ & 2,9 & $16,03^{\star \star}$ & 1,7 & $11,31^{*}$ & 2,3 & $19,80^{* *}$ & 1,6 & $7,82^{*}$ \\
\hline $\begin{array}{l}\text { Verbal, with one so- } \\
\text { lution option }\end{array}$ & 2,2 & & 2,5 & & 1,5 & & 1,7 & \\
\hline
\end{tabular}

Note: *** $p \leq 0,001 ;{ }^{* *} p \leq 0,01 ;{ }^{*} p \leq 0,05$.

In the second group of subjects, significant differences obtained using the Kruskal-Wallis H-test were found among all four indicators of cognitive maps: figurative abstractness (hemp. $=16.03 ; p \leq 0.01$ ), symbolic abstractness (hemp. $=11,31 ; p \leq 0,05$ ), imagery (hemp. $=19.80 ; p \leq 0.01$ ) and symbolism (hemp. $=7,82$; $p \leq 0,05)$. The highest indicators of figurative abstractness (3.3), figurativeness (3.5) and symbolism (2.6) are demonstrated by cognitive maps based on the results of the first type of tasks - nonverbal, with one possible solution. The highest indicators of symbolic abstraction (2.8) were demonstrated by the subjects, creating cognitive maps, based on the results of solving the second type of problem - verbal, with several possible solutions.

The indicators of the figurative abstractness of the cognitive maps performed on the results of nonverbal tasks significantly exceed the indicators of verbal tasks. Cognitive maps based on problems with multiple solutions are inferior in this indicator to problems with a single solution. At the same time, the largest gap in the index of figurative abstractness is observed between cognitive maps created on the basis of verbal and nonverbal tasks.

High symbolic abstractness, on the contrary, is typical for verbal tasks. However, the results in terms of symbolic abstractness are slightly higher for cognitive maps based on the results of solving problems with multiple solutions.

The high rate of imagery that the cognitive map demonstrates is based on a nonverbal task with one solution option, which is not typical for other types of tasks. Cognitive maps based on the third task, despite its nonverbal nature, show a significant decrease in the indicators of imagery, but at the same time, according to these indicators, they are superior to cognitive maps made on the basis of verbal tasks.

A higher symbolism is observed in a map that displays a nonverbal problem with one solution, compared to maps made on the basis of verbal problems with several solutions. However, for verbal tasks, the opposite picture is observed. Cognitive maps based on such tasks show high rates of symbolism in the case of several solutions to it.

Now we shall look at the data on the differences between all the indicators of the cognitive maps performed based on the results of solving each individual type of tasks, with time constraints. The results are presented in table 4 . 
Table 4

Differences between all indicators of cognitive maps performed under time constraints, based on the results of solving each individual type of task

\begin{tabular}{|c|c|c|c|c|c|c|c|c|}
\hline \multirow{3}{*}{$\begin{array}{l}\text { Indicators of } \\
\text { cognitive maps }\end{array}$} & \multicolumn{8}{|c|}{ Types of tasks } \\
\hline & \multicolumn{2}{|c|}{$\begin{array}{c}\text { Task } 1 \\
\text { Nonverbal, with one } \\
\text { solution option }\end{array}$} & \multicolumn{2}{|c|}{$\begin{array}{c}\text { Task } 2 \\
\text { Verbal, with multiple } \\
\text { solutions }\end{array}$} & \multicolumn{2}{|c|}{$\begin{array}{c}\text { Task } 3 \\
\text { Nonverbal, with } \\
\text { multiple solutions }\end{array}$} & \multicolumn{2}{|c|}{$\begin{array}{l}\text { Task } 4 \\
\text { Verbal, with one } \\
\text { solution option }\end{array}$} \\
\hline & $\begin{array}{c}\text { Average } \\
\text { values }\end{array}$ & $\begin{array}{c}\text { Difference } \\
\text { indicator }\end{array}$ & $\begin{array}{c}\text { Average } \\
\text { values }\end{array}$ & $\begin{array}{c}\text { Difference } \\
\text { indicator }\end{array}$ & $\begin{array}{c}\text { Average } \\
\text { values }\end{array}$ & $\begin{array}{c}\text { Difference } \\
\text { indicator }\end{array}$ & $\begin{array}{c}\text { Average } \\
\text { values }\end{array}$ & $\begin{array}{c}\text { Difference } \\
\text { indicator }\end{array}$ \\
\hline $\begin{array}{l}\text { Figurative } \\
\text { abstractness }\end{array}$ & 3,3 & & 1,6 & & 2,9 & & 2,2 & \\
\hline $\begin{array}{l}\text { Symbolic } \\
\text { abstractness }\end{array}$ & 1,8 & & 2,8 & & 1,7 & & 2,5 & \\
\hline imagery & 3,5 & $16,64^{\mathrm{*x}}$ & 2,0 & $14,68^{* x}$ & 2,3 & 5,95 & 1,5 & 4,43 \\
\hline Symbolism & 2,6 & & 2,1 & & 1,6 & & 1,7 & \\
\hline
\end{tabular}

\section{Note: ${ }^{\star \star *} p \leq 0,001 ;{ }^{\star \star} p \leq 0,01 ;{ }^{*} p \leq 0,05$.}

According to the presented data, significant differences established using the Friedman chisquare test were found between the indicators of cognitive maps that were performed based on the results of solving the first $\left(\chi^{2} r\right.$ emp. $\left.=15.519 ; p \leq 0.01\right)$, the second $\left(\chi^{2}\right.$ remp. $\left.=7.82 ; p \leq 0.05\right)$, the third $\left(\chi^{2}\right.$ remp. $\left.=10.03 ; p \leq 0.05\right)$ and the fourth $\left(\chi^{2}\right.$ remp. $\left.=8.45 ; p \leq 0.05\right)$ tasks.

The cognitive maps that were completed on the results of the first task are expected to have the highest values of imagery (3.5) and figurative abstractness (3.3). In such maps, the main information is represented by nonverbal objects of a high level of abstraction, the verbal component is represented to a less extent $(2,6)$, and its abstractness is relatively low $(1,8)$. Among the cognitive maps completed as a result of the second task, the symbolism $(2,1)$, representing the verbal component, only slightly exceeds the imagery $(2,0)$ as a verbal component of the maps. However, symbolic abstractness $(2,8)$ is significantly ahead of figurative abstractness $(1,6)$. In these maps, the verbal and nonverbal components are represented quantitatively in almost equal proportions, but qualitatively differ significantly, using mainly abstract concepts, against the background of specific images. The indicators of cognitive maps performed on the results of the third task demonstrate the predominance of imagery $(2,3)$, over symbolism $(1,6)$ and figurative abstraction $(2,9)$, over symbolic abstraction $(1,7)$. In such maps, the verbal component has a fairly significant predominance over the nonverbal component, with a significant abstraction of images and concreteness of the concepts used. The cognitive maps performed on the results of the fourth task demonstrate the predominance of symbolism $(1,7)$ over imagery $(1,5)$ and symbolic abstraction $(2,5)$, over figurative abstraction $(2,2)$. In these maps, the predominance of the verbal component over the nonverbal one is pronounced weak, and the degree of abstractness of the concepts used is relatively high, with average indicators of the abstractness of images.

The results of the study of the first and second groups of subjects allow us to compare the indicators of the cognitive maps performed in each of them, in order to find differences between them. The calculation of the Mann-Whitney U-test showed the following statistically significant differences between the groups in terms of cognitive maps: between the indicators of figurative abstractness in solving the third Uemp problem. $=21.5 ; p \leq 0.05$; between the indicators of symbolic abstractness in solving the second Uemp problem. $=20.0 ; p \leq 0.05$; between the indicators of symbolic abstractness in solving the fourth Uemp problem. $=21.5 ; p \leq 0.05$; between the indicators of imagery in solving the fourth Uemp problem. $=25.5$; $p \leq 0.05$; between the symbolism indicators when solving the second Uemp problem. $=16.5, p \leq 0.01$; between the symbolism indicators when solving the third Uemp problem. $=11.0 ; p \leq 0.01$; 


\section{Discussions}

It can be assumed that working with a nonverbal task with one correct solution and no time limits was perceived by the participants of the collaborative thinking activity primarily at the nonverbal level. This was evidenced by the high rates of imagery and significantly lower rates of symbolism of cognitive maps. At the same time, the images used in the thought process were of a generalizing, abstract nature. This is evident in the high levels of figurative abstractness of cognitive maps. The indicators of symbolic abstractness, on the contrary, are quite low. Consequently, in the process of solving this type of problem, the verbal component of thinking was concrete, describing the immediate moments of the thought process. This seems to be due to the auxiliary role played by the verbal component of thinking in this case. Abstract images made it possible to work with a large number of ideas that arose in the process of solving the first problem, without having to translate them into verbal form. According to research of S. Deana, when working with information flows, the unconscious translates nonverbal images into conscious, which are realized by the person as necessary (Dehaene, 2011; Dehaene et al., 2014). Due to the nonverbal nature of the task being solved, the translation of a significant part of the information into verbal form was unnecessary. The presence of a certain number of specific words, reflected the final moment of thinking. When the participants of the discussion shared their already formed idea with each other.

Working with a verbal task that has one correct solution and no time limit demonstrates a slightly different picture of thinking activity. According to the low indicators of figurative and symbolic abstractness, the thought process of solving the fourth problem was more concrete than the first one. Apparently, the solution of this problem, almost equally involved both the verbal and nonverbal components of the psyche, which can also be seen in the average indicators of imagery and symbolism. When comparing different options for possible solutions to a problem where only one method is correct, finding such a method requires significant time and effort. Indeed, finding one of the many correct solutions to a problem is statistically easier than finding a single solution. When finding the only correct solution, you need to go through and analyze more options than when finding one of several correct solutions. Apparently, therefore, the problem of speed comes to the fore of thinking activity. In this case, the problem of the speed of thinking was solved by shifting the thinking activity towards the nonverbal unconscious component, as shown in the research of A. Dijksterhuis (Dijksterhuis and Nordgre, 2006). However, the verbal nature of the task prevented them from fully switching to image manipulation, and their thinking activity was forced to balance between their verbal and nonverbal components.

When working with a verbal and nonverbal task that has several solutions, the verbal component of thinking, in the subjects, clearly prevails over the nonverbal, which is noticeable by the increased indicators of the symbolism of cognitive maps. At the same time, figurative abstractness increased when solving nonverbal tasks, while symbolic abstractness remained at an average level. It did not differ much in the cognitive maps drawn from the results of verbal and nonverbal tasks. This seems to be a reflection of the freer, more creative nature of thinking activity in this case. The subjects had to make a choice between several possible solutions, some of which had obvious signs of the correct solution. In such circumstances, it may be necessary to consciously pay attention to the details of possible solutions, pronouncing them for yourself and others, which increases the verbal component of thinking. The results obtained are in many respects similar to the data of the experiments of A. Dijksterhuis and $\mathrm{H}$. Aarts (Dijksterhuis and Aarts 2010). Although these researchers claimed that it is the unconscious that is better suited to solve creative problems, they did not deny that with alternative solutions, the conscious component of the psyche may be more effective. Participants could pay more attention to the discussion of various ideas, compare several correct solutions among themselves, find the best alternative by such a comparison; at the same time, being not limited to strict requirements for the result of the decision. Taking into account the activating function of positive gnostic emotions, which are typical in this case, this approach allowed us to talk more about possible ways to achieve results, express original ideas more freely, and concretize them at the verbal level (Belousova and Belousova, 2020). The increase in the index of nonverbal abstractness in nonverbal tasks can be explained by the need to reflect the nonverbal component of the task, which is of a secondary nature in the verbal task.

The thinking features demonstrated by the subjects when working on a nonverbal problem with one solution that has time constraints are generally similar to the thinking features of the subjects when solving the same problem that does not have time constraints. The reduced use of words in general and abstract concepts in particular seems to have reduced the time needed to formulate them, as it did when solving problems in groups without time constraints. However, these indicators were higher in groups with time constraints. Due to this, it became possible to increase the value of the nonverbal component of thinking. It can be assumed that it was the temporary pressure on the groups that led to 
these features of the manifestation of thought processes. The data obtained correspond to the results of a series of experiments by M. Strick, L. F. Nordgren and R. B. van Baaren, which confirm the idea that the unconscious is able to perform more mental operations than conscious, thereby accelerating thought processes (Strick et al., 2011). This strengthening of the cognitive unconscious contributed to an increase in the share of images and abstract concepts in thinking and made it difficult to translate them into a verbal, fully conscious form in the future.

When working with a nonverbal task that has several solutions with a time limit, the subjects' thinking shows a decrease in imagery, compared to solving a problem with one solution, but exceeds this indicator when solving verbal tasks. This suggests that the presence of several options for solving the problem, with its nonverbal nature, reduced the overall intensity of thinking activity. The relative ease of finding one of several solutions, compared to the need to find the only correct solution, and the nonverbal nature of the task itself, which made it difficult to exchange opinions in a group, made the picture of thinking less rich in images and concepts.

The relatively high symbolic thinking of the subjects who worked on a verbal problem with multiple solutions and time constraints, compared to the maps made on the basis of a problem with a single solution, indicates a reliance on verbal mental processes, with their ability to abstract and generalize. However, due to the relative slowness of the verbal manifestations of thought processes, the use of images gives an advantage in speed. According to the theory of the global workspace of $B$. Baars, thought processes individually work unconsciously (Baars, 2017). However, in order to form a general picture of what is happening, their interaction becomes conscious. In this case, the need to work on different alternatives to solving the problem under time constraints led to the need to simultaneously quickly search for different solutions (using the nonverbal, unconscious component of thinking) and simultaneously integrate the results of these solutions into the overall thought process (using the verbal, conscious component of thinking). This in turn increases the abstractness of symbolic thinking and makes the differences between the indicators of symbolic and figurative abstractness based on verbal tasks more significant than the differences in the indicators of figurative and symbolic thinking.

The differences between the indicators of thought processes implemented without time constraints (the first group) and thought processes implemented with time constraints (the second group) indicate the pressure of the time factor that the thinking of the subjects from the second group experienced. They are more likely than the subjects of the first group to use abstract images and concepts in their thought processes, but in general they use symbols and images in a less balanced way, which is why, as a rule, there is a clear predominance of either one or the other in their thinking. Subjects from the first group are more inclined to use specific words and images in their thought processes, tend to build complex structures, and prefer to adhere to approximately equal use of the verbal and nonverbal components in their thought processes.

\section{Conclusions}

The results obtained in the study make it possible to see the direct interaction of verbal and nonverbal components of thought processes and indirectly observe the dynamics of relations between the conscious and unconscious components of the psyche.

Based on the data obtained, the following conclusions can be drawn:

1. Under the conditions of time constraints, the tendency to use abstract images in thinking activity increases significantly, when the conscious, not having time to formulate thoughts clearly enough in a verbal-logical form and subject them to verbal processing, gives way to the unconscious, which processes information on a nonverbal level and is able to give the necessary description on the basis of unclear, generalized images.

2. When solving nonverbal tasks with time constraints, the use of abstract concepts increases, while in the absence of time pressure, the use of abstract concepts is inferior to the use of abstract images. In the conditions of lack of time, the differentiation of the implementation of verbal and nonverbal processes in thinking activity increases due to the difficulties of double encoding, when the verbal component of thought processes ceases to have time to decipher the nonverbal images generated by the unconscious component of the psyche, and is forced to separate from it.

3. The symbolism of thinking processes in solving verbal problems with multiple solutions is higher than in such problems with a single solution. A large number of solutions to these problems increases the activity of the verbal component of thinking. When solving a nonverbal problem with one correct answer, on the contrary, the imagery of thinking activity in the psyche is higher than when solving a nonverbal 
problem with multiple solutions, which can be explained by the ability of the nonverbal component of thinking to unconsciously conduct a quick search of solutions. Therefore, when thinking about a large number of alternatives with the help of verbal and logical thinking, a person is aware of and, consequently, displays a lot of objects of his thinking activity, which increases the symbolic component of hislher ideas about it. On the contrary, when working with nonverbal elements, imaginative thinking is involved in the analysis of many alternatives, most of them helshe simply does not realize and only when working with one solution, even in a nonverbal form, enough objects are displayed in the psyche to give a fairly complete description of the imaginative thought processes.

4. The figurative component of thinking, prevails over the symbolic, in thinking activity, when solving both verbal and nonverbal tasks. At the same time, the imagery of thought processes when solving problems with one answer is higher than with many, and when solving nonverbal problems, it is higher than verbal ones. This is due to the fact that thinking activity relies on the language of images, which are then translated into verbal representations.

\section{Acknowledgements}

The author expresses gratitude to all the participants of the study-students of the Don State Technical University.

\section{Conflict of interests}

The author declares no conflict of interest.

\section{References}

Baars, B. J. (2017). The Blackwell Companion to Consciousness. In Schneider S, \& Velmans M (Eds), The global workspace theory of consciousness: Predictions and results (2 ed., Pp. 227-242). West Sussex, Chicheste: John Wiley \& Sons Ltd. ISBN: 9780470674062. https://doi.org/10.1002/9781119132363

Beel, J., \& Langer, S. (2011). An exploratory analysis of mind maps. [Abstract]. In Proceedings of the 11th ACM symposium on Document engineering, 81-84. https://doi.org/10.1145/2034691.2034709

Behrens, T. E., Muller, T. H., Whittington, J. C., Mark, S., Baram, A. B., Stachenfeld, K. L. et al. (2018). What is a cognitive map? Organizing knowledge for flexible behavior. Neuron, 100(2), 490-509. https://doi.org/10.1016/j.neuron.2018.10.002

Bellmund, J. L., Gärdenfors, P., Moser, E. I., \& Doeller, C. F. (2018). Navigating cognition: Spatial codes for human thinking. Science, 362(6415), 6766. https://doi.org/10.1126/science.aat6766

Belousova, A., \& Belousova, E. (2020). Gnostic emotions of students in solving of thinking tasks. International Journal of Cognitive Research in Science, Engineering and Education, 8(2), 27-34. https://doi.org/10.5937/IJCRSEE2002027B

Bottini, R., \& Doeller, C. F. (2020). Knowledge across reference frames: cognitive maps and image spaces. Trends in Cognitive Sciences. 24(8), 606-619. https://doi.org/10.1016/j.tics.2020.05.008

Cañas, A. J., Novak, J. D., \& Reiska, P. (2015). How good is my concept map? Am I a good Cmapper?. Knowledge Management \& E-Learning: An International Journal, 7(1), 6-19. https://doi.org/10.34105/j.kmel.2015.07.002

Dehaene, S. (2011) Conscious and Nonconscious Processes: Distinct Forms of Evidence Accumulation? In Duplantier B, \& Rivasseau V (Eds), Biological Physics, (Pp. 141-168). Basel-Stadt, Basel: Springer. ISBN: 978-3-0346-0428-4. https:// doi.org/10.1007/978-3-0346-0428-4_7

Dehaene, S., Charles, L., King, J. R., \& Marti, S. (2014). Toward a computational theory of conscious processing. Current opinion in neurobiology, 25, 76-84. https://doi.org/10.1016/j.conb.2013.12.005

Dijksterhuis, A., \& Aarts, H. (2010). Goals, attention, and (un) consciousness. Annual review of psychology, 61, 467-490. https://doi.org/10.1146/annurev.psych.093008.100445

Dijksterhuis, A., \& Nordgren, L. F. (2006). A theory of unconscious thought. Perspectives on Psychological science, 1(2), 95109. https://doi.org/10.1111/j.1745-6916.2006.00007.x

Downs, R. M., \& Stea, D. (2017). Cognitive Maps and Spatial Behavior: [Electronic version]. In Downs, RM., \& Stea, D (Eds), Process and Products Image and environment: Cognitive mapping and spatial behavior. (2 ed., Pp. 8-27). New York, NY: Transaction Publishers. (Original work published 1973) https://doi.org/10.4324/9780203789155

Eden, C. (2004). Analyzing cognitive maps to help structure issues or problems. European Journal of Operational Research, 159(3), 673-686. https://doi.org/10.1016/S0377-2217(03)00431-4

Epstein, S. (2012). Cognitive-experiential self-theory: An integrative theory of personality. In Millon T, \& Lerner MJ (Eds), Handbook of psychology: Personality and social psychology Vol. 5. (2 ed., Pp. 159-185). New Jersey, Hoboken: John Wiley \& Sons. https://doi.org/10.1002/9781118133880.hop205005

Fauconnier, G. (2018). In Ten Lectures on Cognitive Construction of Meaning. South Holland, Leiden: Brill, 1-23. https://doi. org/10.1163/9789004360716_002

Filomena, G., Verstegen, J. A., \& Manley, E. (2019). A computational approach to 'The Image of the City'. Cities, 89, 14-25. https://doi.org/10.1016/j.cities.2019.01.006

McAleese, R. (1998). The knowledge arena as an extension to the concept map: Reflection in action. Interactive Learning Environments, 6(3), 251-272. https://doi.org/10.1076/ilee.6.3.251.3602 
Milgram, S. (1970). The experience of living in cities. [Electronic version]. Science, 167(3924), 1461-1468. https://doi. org/10.1126/science.167.3924.1461

Nanay, B. (2021). Unconscious mental imagery. Philosophical Transactions of the Royal Society B, 376(1817), 20190689. https://doi.org/10.1098/rstb.2019.0689

Nesbit, J. C., \& Adesope, O. O. (2006). Learning with concept and knowledge maps: A meta-analysis. Review of educational research, 76(3), 413-448. https://doi.org/10.3102/00346543076003413

Novak, J. (2010). Learning, Creating, and Using Knowledge: Concept maps as facilitative tools in schools and corporations. Journal of e-Learning and Knowledge Society, 6(3), 21-30. Retrieved from https://www.learnt echlib.org/p/43512/

Paivio, A. (2011). Dual coding theory, word abstractness, and emotion: A critical review of Kousta et al. Journal of Experimental Psychology: General, 142(1), 282-287. https://doi.org/10.1037/a0027004

Palmiero, M., Piccardi, L., Giancola, M., Nori, R., D’Amico, S., \& Belardinelli, M. O. (2019). The format of mental imagery: from a critical review to an integrated embodied representation approach. Cognitive processing, 20(3), 277-289. https://doi. org/10.1007/s10339-019-00908-z

Park, S. A., Miller, D. S., Nili, H., Ranganath, C., \& Boorman, E. D. (2020). Map making: constructing, combining, and inferring on abstract cognitive maps. Neuron, 107(6), 1226-1238. https://doi.org/10.1016/j.neuron.2020.06.030

Rosch, E. H. (2011). Slow lettuce: Categories, concepts, fuzzy sets, and logical deduction. [Electronic version]. In Belohlavek, R. \& Klir, GJ (Eds), Concepts and fuzzy logic, (Pp. 89-120). Massachusetts, Cambridge: MIT Press. Retrieved from https://www.researchgate.net/publication/221705062_6_Representing_Concepts_by_Fuzzy_Sets

Sadoski, M., \& Paivio, A. (2013). Imagery and text: A dual coding theory of reading and writing. New York, NY: Routledge. https://doi.org/10.4324/9780203801932

Solso, R. L, MacLin, O. H., \& MacLin, M. K. (2014). Cognitive Psychology: Pearson New International Edition. Essex, Harlow: Pearson. Retrieved from https://ru.scribd.com/document/436463162/Solso-Robert-L-Cognitive-Psychology-Pearson2013-KOGNITIF-pdf

Stern, D. B. (2015). Relational freedom: Emergent properties of the interpersonal field. New York, NY: Routledge. ISBN: 9781315765570. https://doi.org/10.4324/9781315765570

Strick, M., Dijksterhuis, A., Bos, M. W., Sjoerdsma, A., Van Baaren, R. B., \& Nordgren, L. F. (2011). A meta-analysis on unconscious thought effects. Social Cognition, 29(6), 738-762. https://doi.org/10.1521/soco.2011.29.6.738

Sweller, J. (2020). Cognitive load theory and educational technology. Educational Technology Research and Development, 68(1), 1-16. https://doi.org/10.1007/s11423-019-09701-3

Tolman, E. C. (1948). Cognitive maps in rats and men. Psychological review, 55(4), 189. https://doi.org/10.1037/h0061626

Ward, T. B., Finke, R. A., \& Smith, S. M. (2013). Creativity and the mind: Discovering the genius within. Massachusetts, Boston: Springer. (Original work published 1995) ISBN: 978-1-4899-3330-0 https://doi.org/10.1007/978-1-4899-3330-0 